\title{
Desmoplastic small round cell tumour in a 74 year old man: an uncommon cause of ascites (case report)
}

\author{
Andrew J Heikkila ${ }^{1 *}$ and Ally PH Prebtani ${ }^{2}$
}

\begin{abstract}
A rare case is provided of a 74 year old man who presented with ascites of unknown etiology. CT scan of the abdomen revealed extensive omental caking, and omental biopsy cytogenetics showed findings in keeping with a diagnosis of desmoplastic small round cell tumour (DSRCT). This case is unique in that it involves a significantly older patient, negative WT1 immunohistochemical staining, and negative cytology. Despite repeated paracenteses and fluid management, the patient died in hospital secondary to renal complications.
\end{abstract}

Virtual Slides: The virtual slide(s) for this article can be found here: http://www.diagnosticpathology.diagnomx.eu/ vs/7545323065298756.

\section{Background}

DSRCT is an exceedingly rare malignancy, first described by Gerald and Rosai in 1989. Characterized by a predilection for young males, it typically presents as an intraabdominal mass with multiple intra-peritoneal implants, and has a dismal 5-year survival rate. Recent years have brought forth invaluable information regarding the immunohistochemical and cytogenetic features of this tumour. Below we present a recent case of DSRCT in a 74 year old man who presented with ascites. Investigations interestingly revealed negative WT1 staining and cytology. This is followed by a discussion of key clinical and investigational findings that aided in diagnosis, as well as an approach to unusual causes of ascites.

\section{Case Presentation}

A 74 year old man presented to hospital with a six week history of increasing abdominal girth, worsening umbilical pain, decreased appetite, and a six month history of significant unintentional weight loss. His past history was significant for an excised rectal tubular adenoma, Benign Prostatic Hypertrophy, and Gastroesophageal Reflux Disease. He was a non-smoker and a non-

\footnotetext{
* Correspondence: andrew.heikkila@medportal.ca

'McMaster University, Department of Anesthesia, Health Sciences Centre

2U1, 1200 Main Street West, Hamilton, Ontario, Canada Full list of author information is available at the end of the article
}

drinker. He had recently been prescribed Spironolactone $25 \mathrm{mg}$ daily for his ascites and he took Rabeprazole 20 mg daily. Initially, the patient's blood pressure was 124/ 80 , pulse 115 and regular, respiratory rate 20 , and he was afebrile. The abdomen was distended with bulging flanks. There was a fluid wave and shifting dullness. There were no signs of chronic liver disease. Cardiovascular exam was normal, with no murmurs or extra heart sounds, and the JVP was $2 \mathrm{~cm}$. Breath sounds were heard to the lung bases bilaterally with no crackles. There was no peripheral edema and no evidence of lymphadenopathy of the head and neck or groin.

A computed tomography (CT) scan of the abdomen showed extensive omental caking and ascites (Figures 1 and 2). This was seen as heterogenous nodular enhancement of the omentum with marked dense free fluid in the abdominal and pelvic cavities. The liver and bowels were unremarkable. No bony lesions were seen. Multiple enlarged paraaortic lymph nodes with the absence of central hilar fat were noted. CT of the chest did not demonstrate any lesions.

Therapeutic and diagnostic paracenteses were performed, which revealed visibly bloody peritoneal fluid. Analysis was negative for malignant cells on both occasions. The differential cell count was: monocytes $14 \%$, lymphocytes $67 \%$, and neutrophils $19 \%$. The serum and fluid albumin values were $33 \mathrm{~g} / \mathrm{L}$ and $25 \mathrm{~g} / \mathrm{L}$,
C Biomed Central 


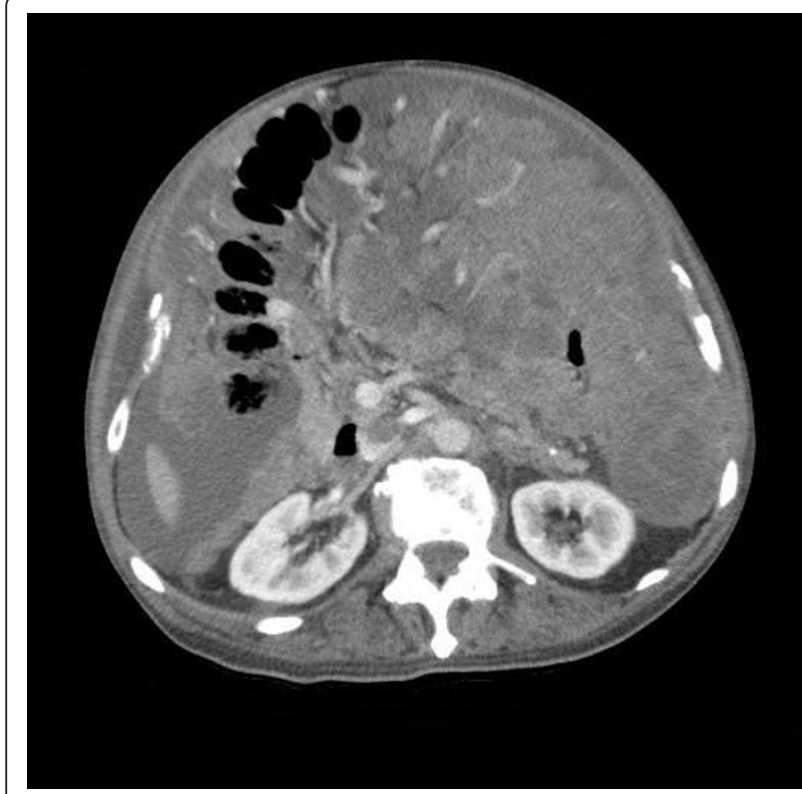

Figure 1 Axial $5 \mathrm{~mm} \mathrm{CT} \mathrm{slice,} \mathrm{at} \mathrm{the} \mathrm{level} \mathrm{of} \mathrm{the} \mathrm{renal} \mathrm{hilum,}$ demonstrating dense omental caking, high density fluid with increased omental vascularity

respectively, giving a serum-ascites albumin gradient (SAAG) of $8 \mathrm{~g} / \mathrm{L}$, suggestive of non-portal hypertension ascites. Cultures of the fluid were negative for infection.

Ultrasound guided omental biopsies were performed. Microscopic analysis showed neoplastic small round blue cells arranged in sheets, without a desmoplastic

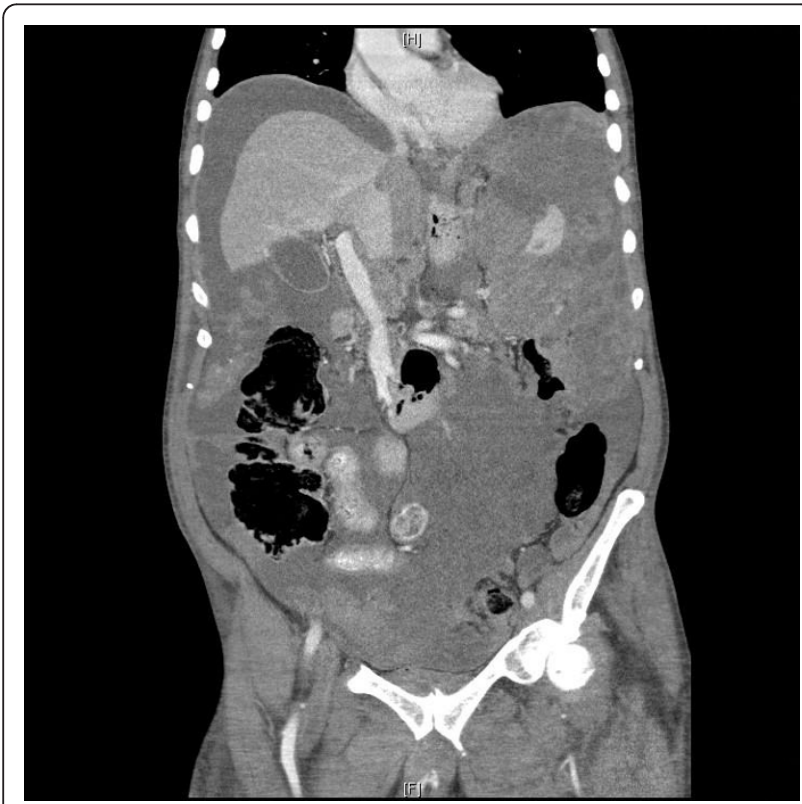

Figure 2 Coronal CT view demonstrating marked omental caking with interspersed high density fluid filling the left hypocondrium and left peritoneal region.

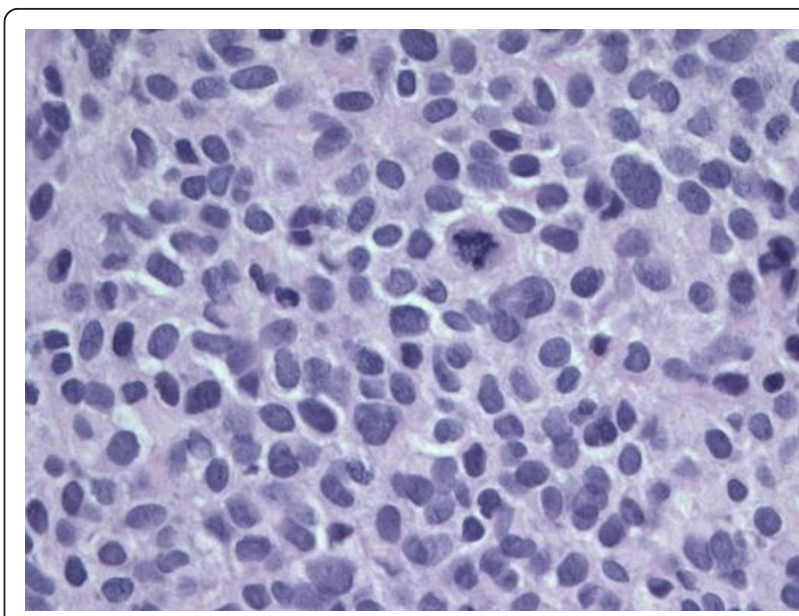

Figure 3 Microphotograph representative of the core biopsy material demonstrating a diffuse population of small undifferentiated malignant cells. [Hematoxylin and Eosin stain, $400 \times$.]

stroma (Figure 3). The cells possessed large hyperchromatic nuclei and amphophilic cytoplasm. There were scattered mitoses, less than 1 per $10 \mathrm{HPF}$ with foci of microscopic necrosis.

Immunohistochemistry showed a strong positive desmin staining of cytoplasm and punctate (Figure 4). There were scattered cells positive for CAM 5.2, punctate pattern (Figure 5), as well as rare EMA positive cells. Staining for Ki-67 with MIB-1 was positive in up to $35 \%$ of tumour cells (Figure 6), and the cells were negative for WT1.

Several days later, cytogenetics results were available and demonstrated the presence of EWS/WT-1 fusion transcriptase arising from the $(11 ; 22)$ translocation, characteristic of DSRCT.

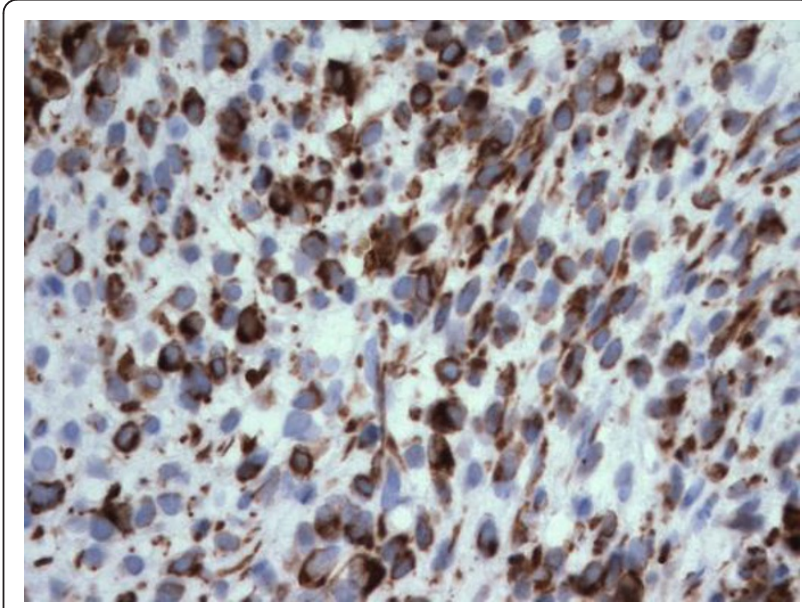

Figure 4 Microphotograph demonstrating cytoplasmic diffuse and punctate staining of malignant cells for desmin. [400 $\mathrm{X}$.] 


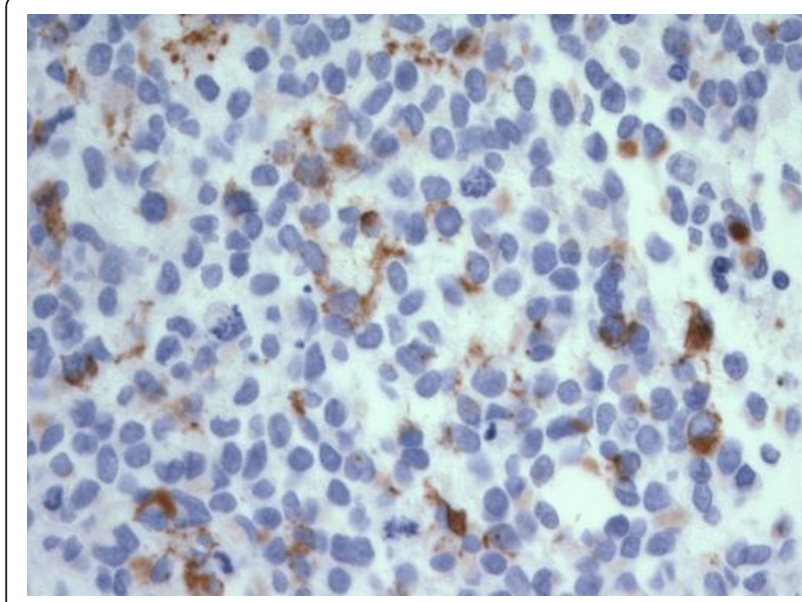

Figure 5 Microphotograph demonstrating cytoplasmic, punctate staining of malignant cells for Cam 5.2. [400 X.]

By the third week of admission, despite repeated therapeutic paracenteses, the patient had significantly deteriorated. He became bed bound, anorexic, and weak. He developed impressive peripheral edema with ongoing tense ascites, leading to intravascular fluid depletion. He was hypotensive and in acute renal failure with hyperkalemia. The decision was made for comfort measures only after the final pathological diagnosis. He passed away shortly thereafter. An autopsy was not performed.

\section{Discussion}

DSRCT is an exceptionally rare malignancy, first described by Gerald and Rosai in 1989 [1]. Characterized by a predilection for young males, it typically presents as an intra-abdominal mass with multiple intraperitoneal implants, and has a 5 -year survival rate of

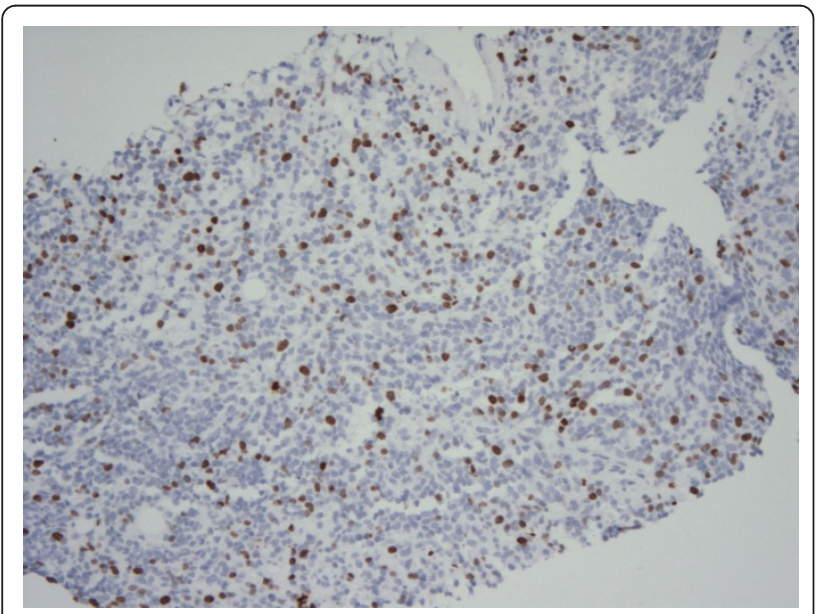

Figure 6 Microphotograph demonstrating positive Ki-67 staining in nearly $35 \%$ of tumour cells. [MIB-1 stain, $100 \times$.]
$15 \%$ [2]. Our patient died approximately 7 months following the onset of symptoms.

As with all medical diagnoses, that of DSRCT involves a thorough history, physical examination and series of investigations. Our patient certainly did not fit the usual demographics for DSRCT, a disease that typically affects adolescents and young adults. However, his clinical findings of abdominal pain, anorexia, and ascites, though non-specific for DSRCT, represent three of the more commonly described signs and symptoms of this malignancy [3].

In Cao et al. report of 18 DSRCT cases, five of the patients presented with ascites [3]. Lae et al. documented ascites occurring in only two of 18 DSRCT cases [4]. Thus, ascites is a clinical component of this disease, though it rarely occurs in isolation. Furthermore, ascites has a broad differential diagnosis which warrants a methodical workup.

Cirrhosis accounts for more than $85 \%$ of cases of ascites, with the remaining $15 \%$ caused by congestive heart failure, malignancy, and other less common diseases. Malignancy accounts for approximately two-thirds of non-cirrhotic ascites [5]. When confronted with ascites, a thorough clinical history is essential in differentiating hepatic from nonhepatic causes. A discussion of risk factors for liver disease, including alcohol use and viral hepatitis, as well as a history of cardiac disease should be sought. An episode of new onset ascites accompanied by abdominal pain is suspicious for malignancy [6].

Physical examination is equally important in the workup of ascites. Fluid wave and shifting dullness are among the most specific markers of ascites $(90 \%$ and $72 \%$, respectively), whereas flank dullness, bulging flanks, and shifting dullness are the most sensitive (84\%, $81 \%$, and $77 \%$, respectively) [7]. Examination beyond the abdomen may demonstrate palmar erythema, gynecomastia, and spider nevi, suggestive of liver disease. An elevated jugular venous pressure suggests congestive heart failure or constrictive pericarditis. Generalized edema, particularly of the face and upper limbs, suggests nephrotic syndrome. The absence of these unique clinical findings pushes more towards a malignant etiology.

Malignant ascites often occurs when the malignancy is advanced or recurrent. Urinary bladder and ovarian malignancies, as well as cancers of the colon, stomach and pancreas can cause peritoneal carcinomatosis with associated ascites [8]. DSRCT is an exceedingly rare cause of malignant ascites. However, features of ascitic fluid can narrow the differential within this malignancyrelated group.

Ascitic fluid analysis should be routinely performed in any patient with new-onset ascites. $20 \mathrm{~mL}$ of fluid should be placed in two blood culture bottles at the bedside, and another $10 \mathrm{~mL}$ should be sent for cell 
count and albumin. Fluid cytology may be ordered if malignancy is high on the differential. A serum albumin should be drawn at the same time.

The gross appearance of ascitic fluid can be modestly helpful in elucidating the etiology. $20 \%$ of malignant ascites fluid is grossly bloody, as in our case, though more than half of such cases are due to hepatocellular carcinoma [8]. Only $5 \%$ of cirrhotic ascites is bloody. Cell count and differential are useful in identifying spontaneous bacterial peritonitis, although the white cell count is generally also elevated in malignancy-related ascites [6]. Cytology may be extremely valuable in suspected malignancy, being positive in $97-100 \%$ of cases of peritoneal carcinomatosis, but was surprisingly negative in our case [6].

The SAAG, a parameter of oncotic pressure gradient, has been used for more than two decades to distinguish portal hypertension-related ascites from all other causes with a diagnostic accuracy of $97 \%$ [5]. An elevated SAAG (11 g/L or greater) correlates with portal hypertension, whereas a low gradient indicates no portal hypertension. Table 1 outlines common pathologies associated with both high and low SAAG values [6]. In our case, a SAAG of $8 \mathrm{~g} / \mathrm{L}$, when combined with the patient's clinical features, certainly favoured a malignant diagnosis.

Tumour analysis, most notably immunohistochemical and cytogenetic studies, has enhanced our ability to diagnose DSRCT and has identified it as a unique clinical entity. Microscopically, the biopsy samples in our case fit the well-documented description of small round blue tumour cells, although there was minimal surrounding desmoplastic stroma. Typically, the tumour cells are separated by plentiful stroma [9].

Histologically and cytogenetically, DSRCT shares features with other round cell tumours including small cell carcinoma, mesothelioma, Wilms' tumour, and Ewing's sarcoma/peripheral neuroectodermal tumours (PNET). DSRCT cells are normally reactive for keratin, epithelial membrane antigen, desmin, vimentin, and neuron-specific enolase $[4,10-15]$. Small cell carcinoma often lacks

Table 1 Ascites Etiologies by Serum-Ascites Albumin Gradient (SAAG)

\begin{tabular}{cc}
\multicolumn{2}{c}{ Ascites Etiologies by SAAG } \\
\hline SAAG $\geq 11 \mathrm{~g} / \mathbf{L}$ & SAAG $<11 \mathrm{~g} / \mathrm{L}$ \\
Cirrhosis & Peritoneal carcinomatosis \\
Congestive heart failure & Pancreatitis \\
Alcoholic hepatitis & Nephrotic Syndrome \\
Hepatic metastases & Serositis \\
Portal vein thrombosis & Tuberculosis \\
Budd-Chiari syndrome & \\
\hline
\end{tabular}

An elevated SAAG (11 g/L or greater) correlates with portal hypertension, whereas a low gradient indicates no portal hypertension [6]. desmoplastic stroma and is not immunoreactive with desmin [16]. In our case, desmin was positive and demonstrated the unique punctate and cystoplasmic staining. Interestingly, WT1 was negative, a finding unusual for DSRCT. More than 70\% of DSRCT cases are positive for WT1 [17], a finding which has also been shown with mesothelioma and Wilms' tumour [18]. Mesothelioma can often be distinguished by positive calretinin expression $[17,19,20]$, while Wilms' tumour lacks the characteristic chromosomal translocation and occurs in a much younger patient population [9]. In our patient, cytogenetic studies revealed the typical $t(11 ; 22)$ translocation involving the short arm of chromosome 11. Ewing's sarcoma, which shares many features with DSRCT, is distinguished by a similar translocation which instead involves the long arm of chromosome 11 [21].

\section{Conclusions}

In summary, DSRCT is a rare and highly aggressive, cytogenetically unique malignancy. It represents an exceedingly uncommon cause of ascites. The above case shared many features with those previously reported in the literature, with the exceptions of significantly older patient age, negative WT1 immunohistochemical staining, and negative cytology. A methodical diagnostic strategy, moving from history to imaging, ascitic fluid studies and tumor analysis, can reliably make the diagnosis of DSRCT.

\section{Consent}

Written informed consent was obtained from the patient's family for publication of this case report and any accompanying images. A copy of the written consent is available for review by the Editor-in-Chief of this journal.

\section{Acknowledgements}

The authors thank Dr. F. DeNardi, Associate Professor, Department of Pathology, McMaster University and Henderson Hospital, and Dr. H. Choudur, Department of Radiology, McMaster University, for their figure and caption contributions.

\section{Author details}

'McMaster University, Department of Anesthesia, Health Sciences Centre 2U1, 1200 Main Street West, Hamilton, Ontario, Canada. ${ }^{2}$ Hamilton General Hospital, 237 Barton Street, Hamilton, Ontario, Canada.

\section{Authors' contributions \\ $\mathrm{AH}$ participated in collecting clinical data and images and drafting the manuscript. AP participated in its design and coordination and helped to draft the manuscript. All authors have read and approved the final manuscript.}

\section{Competing interests}

The authors declare that they have no competing interests. 
1. Gerald WL, Rosai J: Desmoplastic small cell tumor with divergent differentiation. Pediatr Pathol 1989, 9:177-183.

2. Lal DR, Su WT, Wolden SL, Loh KC, Modak S, La Quaglia MP: Results of multimodal treatment for desmoplastic small round cell tumors. J Pediatr Surg 2005, 40:251-255

3. Cao L, Ni J, Que R, Wu Z, Song Z: Desmoplastic small round cell tumor: a clinical, pathological, and immunohistochemical study of 18 Chinese cases. Int J Surg Pathol 2008, 16:257-262.

4. Lae ME, Roche PC, Jin L, Lloyd RV, Nascimento AG: Desmoplastic small round cell tumor: A clinicopathologic, immunohistochemical, and molecular study of 32 tumors. Am J Surg Pathol 2002, 26:823-835.

5. Runyon BA, Montano AA, Akriviadis EA, Antillon MR, Irving MA, McHutchison JG: The serum-ascites albumin gradient is superior to the exudate-transudate concept in the differential diagnosis of ascites. Ann Intern Med 1992, 117(3):215-220.

6. McHutchison JG: Differential diagnosis of ascites. Semin Liver Dis 1997, 17(3):191-202.

7. Williams JW Jr, Simel DL: Does this patient have ascites? JAMA 1992, 267(19):2645-2648.

8. Runyon BA, Hoefs JC, Morgan TR: Ascitic fluid analysis in malignancyrelated ascites. Hepatology 1988, 8:1104-1109.

9. Chang F: Desmoplastic Small Round Cell Tumors: Cytologic, Histologic, and Immunohistochemical Features. Arch Pathol Lab Med 2006, 130(5):728-732.

10. Amato RJ, Ellerhorst JA, Ayala AG: Intraabdominal desmoplastic small round cell tumor: Report and discussion of five cases. Cancer 1996, 78:845-851.

11. Gerald WL, Ladanyi M, de Alava E, Cuatrecasas M, Kushner BH, La Quaglia MP, Rosai J: Clinical, pathologic, and molecular spectrum of tumors associated with $\mathrm{t}(11 ; 22)(\mathrm{p} 13 ; \mathrm{q} 12)$ : desmoplastic small round-cell tumor and its variants. J Clin Oncol 1998, 16:3028-3036.

12. Akhtar M, Ali MA, Sabbah R, Bakry M, al-Dayel F: Small round cell tumor with divergent differentiation: cytologic, histologic, and ultrastructural findings. Diagn Cytopathol 1994, 11:59-64

13. Crapanzano JP, Cardillo M, Lin O, Zakowski MF: Cytology of desmoplastic small round cell tumor. Cancer 2002, 96:21-31.

14. Dave B, Shet T, Chinoy R: Desmoplastic round cell tumor of childhood can cytology with immunohistochemistry serve as an alternative for tissue diagnosis? Diagn Cytopathol 2005, 32:330-335.

15. Das DK, Bhambhani S, Chachra KL, Murthy NS, Tripathi RP: Small round cell tumours of the abdomen and thorax: role of fine needle aspiration cytologic feature in the diagnosis and differential diagnosis. Acta Cytol 1997, 41:1035-1047.

16. Devoe K Weidner N: Immunohistochemistry of small round-cell tumors. Semin Diagn Pathol 2000, 17:216-224.

17. Zhang PJ, Goldblum JR, Pawel BR, Fisher C, Pasha TL, Barr FG: Immunophenotype of Desmoplastic Small Round Cell Tumors as detected in cases with EWS-WT1 gene fusion product. Mod Pathol 2003, 16(3):229-235

18. Little M, Wells C: A clinical overview of WT1 gene mutations. Hum Mutat 1997, 9:209-225

19. Doglioni C, Tos AP, Laurino L, luzzolino P, Chiarelli C, Celio MR, Viale G: Calretinin: a novel immunocytochemical marker for mesothelioma. Am J Surg Pathol 1996, 20:1037-1046.

20. Rogers $\mathrm{JH}$ : Calretinin: a gene for a novel calcium-binding protein expressed principally in neurons. J Cell Biol 1987, 105:1343-1353.

21. Ladanyi M, Gerald W: Fusion of the EWS and WT1 genes in the desmoplastic small round cell tumor. Cancer Research 1994, 54:2837-2840.

doi:10.1186/1746-1596-6-55

Cite this article as: Heikkila and Prebtani: Desmoplastic small round cell tumour in a 74 year old man: an uncommon cause of ascites (case report). Diagnostic Pathology 2011 6:55.

\section{Submit your next manuscript to BioMed Central and take full advantage of:}

- Convenient online submission

- Thorough peer review

- No space constraints or color figure charges

- Immediate publication on acceptance

- Inclusion in PubMed, CAS, Scopus and Google Scholar

- Research which is freely available for redistribution

Submit your manuscript at www.biomedcentral.com/submit
C Biomed Central 